Bands of a very similar nature have been reported in diamond by Raman and Rendall ${ }^{5}$, and investigated in detail by Ramachandran ${ }^{6}$. These authors attribute the bands to the stresses set up in alternate layers of diamond having two different lattice spacings. It would be interesting to know whether they are not really the consequence of plastic deformation.

Examination of a plastically deformed strip of silver chloride that was annealed in stages shows that heating near the melting point causes a gradual reduction of the intensity of the picture, but leaves the pattern unaltered. We may conclude that, during annealing, there occur no large-scale migrations of dislocations, but only localized processes of atomic rearrangement.

Although they are optically isotropic when unstressed, cubic crystals under stress behave differently from glass and the usual plastics used in photo-elastic tests. The crystal classes $T_{d}, O, O_{h}$ require not two but three constants to describe their photo-elastic behaviour, and, as has recently been pointed out ${ }^{7,8}$, the $T$ and $T_{h}$ classes (also in the cubic system) require four. This fact makes the full interpretation of the stress birefringence pattern dependent upon a knowledge not only of certain combinations of these constants, but also of the crystallographic orientation of the grains concerned. It also leads to a striking phenomenon observed in the elastic stress range: when a bending moment is applied to an annealed strip, viewed either between crossed nicols or in a circular polariscope, the grain boundaries are seen to flash out brightly. The effect is completely reversible; if the load is removed the light regions return to their original dark state. The explanation seems to be that, when the bending moment is applied, the light passing through a grain traverses a layer of tension on one side of the strip and a layer of compression on the other side. The birefringence of the two layers cancels out, and the total path-difference between the two oppositely polarized rays will be zero. However, grains with different crystallographic orientations will have different stress-optical constants; consequently, whenever a grain boundary is not perpendicular to the sheet, rays crossing the boundary will pass through different grains on the tensile and com. pressive sides, and the total path difference will not vanish. In contrast to the grains themselves, therefore, the grain boundaries will be lightened. A more exact mathematical treatment of the effect is possible and its results are supported by other observations, but the above argument contains the essence of the explanation. Such bending moments cause the lightening seen at some of the grain boundaries in Fig. 1.

A fuller account of these and other photo-elastic experiments on plastically deformed materials, carried out with the financial support of the British Iron and Steel Research Association, will be published elsewhere. I am greatly indebted to Dr. E. Orowan for suggesting the possibility of using transparent, polycrystalline materials in the way described and for discussion of the results. 1 Brewster, "A Treatise on Optics", 280, 281 (Longman, Brown Green
and Longmans, London. New edit., 1853).

2 Reusch, E., Ann. Phys., [V], 132, 441 (1867).

Obreimow, I. W., and Schubnikoff, L. W., Z. Phys., 41, 907 (1927).

- Orowan, E., Nature, 149, 643 (1942).

saman, Sir C. V., and Rendall, G. R., Proc. Ind. Acad. Sci., 19 A, 265 (1944).

- Ramachandran, G. N., Proc. Ind. Acad. Sci., 24 A, 65 (1946).

'Bhagavantam, S., Proc. Ind. Acad. Sci., 16 A, 359 (1942).

- Bhagavantam, s., and Suryanarayana, D, Proc. Ind. Acad. Sci., 26, $9 *$ (1947); Nature. 160, 750 (1947)

\section{SCIENTIFIC RESEARCH AND INDUSTRY}

GIR EDWARD APPLETON'S address to the $\checkmark$ Scottish Council (Development and Industry) at Glasgow on February 13 on "Science and the Progress of Industry" will increase the impatience with which the scientific and industrial world awaits the resumption of publication of the annual reports of the Department of Scientific and Industrial Research. Indeed, it could well be held that here again, as in the recent speech at Letchworth of the Lord President of the Council (see Nature, February 7, p. 214), by using a speech to a sectional or limited audience, which even in normal times could only be imperfectly reported in the Press, as the occasion for important announcements of policy or disclosure of developments, the Government is showing lack of courtesy to the scientific man and to the industrialist. Such statements should be put on permanent record in a proper fashion. Whatever may be the rights and wrongs of any policy-for example, the present dispute between the Government and the medical profession-it is to be hoped that the Government will learn that it is wiser to court than to flout the expert and professional experience upon the cooperation of which the smooth running of so many Departments of State depends. As Burke once remarked in another connexion, magnanimity in politics is not seldom the truest wisdom, and little minds go ill with a great State department or with a great Empire.

After a tribute to the work of Scottish men of science in the past, Sir Edward suggested that for an overall picture of the pattern of the scientific effort in Great Britain, it is useful to think of its three great sections-research in universities and technical colleges, Government research and research in industry itself-as being situated at the three corners of a triangle and thus linked directly together. $\mathrm{He}$ believes that the first task is to foster fundamental research in universities and technical colleges, where the really revolutionary industrial advances usually have their origin. Such fundamental research knows no national frontiers, but Sir Edward paid here a further tribute to the Scottish contribution, before referring more specifically to the essential contribution of the geologist to those problems of making the best use of familiar materials and of developing in the national interest materials so far regarded as economically useless. The Scottish Branch of the Geological Survey was always ready to help, but the problems of application involved belong to other branches of science. If the inquiries now being carried out by the Scottish Council revealed gaps in the facilities available for research, the Department of Scientific and Industrial Research would always be ready to consult with the Council as to how they could best be filled.

Before dealing with the work of the Department itself, Sir Edward indicated a few of the special grants made to workers in the Scottish universities; for example, to Prof. P. I. Dee in Glasgow and Prof. N. Feather in Edinburgh for work on nuclear physics, to Dr. C. Horrex at St. Andrews for work on the relative speeds of the decomposition of certain organic compounds, to Prof. G. D. Preston at Dundee for work on the development and use of the electron microscope, and to Prof. R. N. Arnold at Edinburgh for work on the cutting of metals at high speeds. 
Emphasizing then the national character of the thirteen research stations of the Department, Sir Edward admitted that while, for example, the work which is being done in developing the science of building is equally applicable north and south of the Tweed, in considering the application of such science to particular problems, there may be considerable difference between the problems of the south of England and those of Scotland. For this reason, it has been decided to establish at East Kilbride branches of the Road Research Laboratory, the Building Research Station and the Fuel Research Station.

Sir Edward said that in co-operation with the County Surveyor of Lanarkshire and the Ministry of Transport, full-scale experimental surfacings are already under observation in that county. Two of these are duplicates of experiments on the Colnbrook Bypass near London, one being concerned with longlife asphalt and the other with tar and bitumen carpets. The object of both these experiments is to ascertain how far conclusions, valid in the south of England, are also valid in Scotland, where the weather tends to be wetter and cooler. Another experiment in Lanarkshire is concerned with the use of wetting agents to improve the adhesion of bituminous binders to a local stone. The County Surveyor of Ayrshire is co-operating in experiments in the use of quarry waste in bituminous surfaces; the County Surveyor of Wigtownshire in the use of local sands, and the County Surveyor of Dumfriesshire in experiments on the use of chemicals for removing ice from roads.

Again, the Building Research Station has carried out work in conjunction with the Scottish Department of Agriculture on building materials composed of peat and cement, and investigations have been made into the suitability of clays from north-east Scotland for brick manufacture. There is already close association between the Fuel Research Station and the manufacturers and others interested in fuel problems in Scotland; but co-operation will be further strengthened by the establishment at East Kilbride of a sub-station of the Fuel Research Organisation. This sub-station will, in the first place, be occupied mainly in testing domestic heating appliances, but it will also serve as a liaison establishment in dealing with other local fuel problems and will ensure full appreciation at Greenwich of Scottish conditions and preferences.

The new laboratory for research into mechanical engineering science of the Department of Scientific and Industrial Research is also to be erected at East Kilbride. Sir Edward said that when, after the War, the Advisory Council for Scientific and Industrial Research came to review the research needs of Great Britain, certain gaps were evident in the facilities for research in this field. The most important of these were in hydraulic machinery, pumps and so forth, in heat transfer problems, in applied thermodynamics, and in kinetics and mechanisms. It will be part of the job of the new establishment to fill in these gaps; but its main task will be basic research in mechanical engineering science, which will have general application in due course throughout the whole of the indus. try. The work has been divided into groups which are, in fact, the underlying subjects of general application in many branches of mechanical engineering; in addition to those already mentioned, the properties of metals, problems of vibration, of lubrication, of noise, and of the mechanies of the formation and machine-shaping of metals are included.
Speaking of the research associations, Sir Edward made two interesting comments. Thirty-five industries now possess active research associations, some, such as the Iron and Steel, and the Electrical Research Associations with incomes of the order of $£ 250,000$ a year, and all with incomes permitting the prosecution of research on a substantial scale, possibly three or four times the pre-war scale. This increase in the scale of working, he suggested, largely disposes of the basis of previous criticism of co-operative research. Secondly, he referred to the use by certain associations, such as the Cotton, the Refractories and the Iron and Steel Research Associations, of the technique of what was called during the War 'operational research'. In industry this means obtaining a quantitative estimate of the dependence of the efficiency of industrial operations on various factors, and studies already made in some branches of industry have indicated immediate steps which could be taken to increase output by as much as twenty per cent. Statistical studies of a different kind made by the Boot and Shoe Research Association have shown that it is possible to increase the chance of being able to fit any customer and to reduce materially the number of sizes to be manufactured and stocked.

of research by individual firms, Sir Edward remarked that the ultimate decision on how far new ideas springing from science are to be applied in industry rests with industry itself, and the manner of that application is a problem to be determined by the management. Nor is any generalization possible as to the necessity for, or type of, research department in an individual firm : there are industries which can safely rely on research carried out for them in out. side organisations, provided they have the technical staff capable of interpreting the results of the work and applying and developing it to meet their particular requirements. No firm can afford to neglect such development, and Sir Edward insisted that Britain can only remain a great industrial nation if the industrial scene is kept under view and opportunities watched for applying science. This is work that the Scottish Council is well equipped to do for Scotland, and the office which the Department of Scientific and Industrial Research has established in Edinburgh is intended to assist the Council in such work. A main task of this new office is to assist the utilization of existing knowledge by putting the man with the problem into direct touch with the man who can solve it.

\section{FORTHCOMING EVENTS}

(Meetings marked with an asterisk * are open to the public)

\section{Monday, March 8}

Institute of Petroledm, Northern Branch (at the Engineers' Club, Albert Square, Manchester), at 6 p.m.-Mr. E. Thornton: "The Fighting of Oil Fires".

ROYAL INSTITUTE OF ChEMISTRY, LONDON AND SODTH-EASTERN ROYAL INSTITUTE OF CHEMISTRY, LONDON AND SOUTH-EASTERN
COUNTIES SECTION (at Woolwich Polytechnic, Woolwich, London, S.E.18), at 6.45 p.m.-Dr. H. Baines: "Colour Photography".

Textile InstiTute (at 16 St. Mary's Parsonage, Manchester), at 7 p.m.-Dr. B. P. Ridge: "Some Aspects of Synthetic Fibres".

INSTITUTION OF THE RUBBER INDUSTRY, MIDLAND SECTION (at Burton-on-Trent), at 7.15 p.m.-Mr. L. E. Puddefoot: "Rubber Adhesives".

\section{Tuesday, March 9}

University College, London (in the Anatomy Theatre, Gower Street, London, W.C.1), at 1.15 p.m.-Prof. H. E. M. Barlow : "Applications of Micro Waves".

ROFAL ANTHROPOLOGICAL INSTITLTE (at 21 Bedford Square, London, W.C.1), at 5 p.m.- Prof. W. E. Le Gros Clark, F.R.S. "Recent Discoveries of Fossil Hominoids in Africa". 